\title{
A Comparison of Psychiatric and Psychological Assessments of Acute Schizophrenics
}

\author{
Eugene I. Burdock, Anne S. Hardesty, William A. Frosch, \\ Samuel Gershon, and Philip Greco \\ New York University School of Medicine
}

\begin{abstract}
Psychiatric and psychological ratings of psychopathology were compared by means of canonical correlation of scores on the Inpatient Multidimensional Psychiatric Scale (IMPS) syndromes with scores on the 10 subtests of the Structured Clinical Interview (SCI). The ratings by a team of psychologists on the SCI and by a team of psychiatrists on the IMPS were made simultaneously, while one of the psychologists conducted the structured interview of the SCI. In this way, 72 acute schizophrenics were rated shortly after admission to a psychiatric hospital; 58 of them were re-rated approximately one month later in a replication of the original procedure. Two canonical analyses were carried out: one on the initial ratings, the second on the replication. Canonical correlations of .84 and .86 were obtained respectively for the first latent roots at each occasion. Successive significant roots yielded correlations of .78 and .68 on the initial ratings and $.76, .69$, and .64 on the follow-up ratings. After all 10 latent roots had been extracted for each occasion of rating, redundancy coefficients were calculated for each instrument. The results showed that for the initial ratings $30 \%$ of each instrument's variance could be explained by the other instrument; at the follow-up ratings the redunancies were $40 \%$ for both sets of variables. The data are interpreted as evidence for the congruent validity of the SCI.
\end{abstract}

Techniques for the quantitative assessment of psychiatric patients have proliferated since the

APPLIED PSYCHOLOGICAL MEASUREMENT

Vol. 2, No. 2 Spring 1978 pp. 175-187

(c) Copyright 1978 West Publishing Co. introduction of psychotropic drugs in the $1950 \mathrm{~s}$, largely because of demands for objective evidence of efficacy. Lorr's article on rating scales (1954), Lyerly's (1973) Handbook of Psychiatric Rating Scales, and Klett's (1968) discussion of assessment of change in psychiatric patients reflect the increasing methodological sophistication that makers and users of these scales acquired during this period. Lorr (1953) and Wittenborn (1955) were groundbreakers in this area, as were McReynolds and Ferguson (1953). Moreover, their scales are still respected instruments today owing to the attention their authors paid to psychometric requirements, whereas many other older scales have foundered because of weaknesses in reliability, validity, and clinical meaningfulness. Among the newer scales that have received general acceptance are: the Brief Psychiatric Rating Scale (BPRS) of Overall and Gorham (1962); the Ward Behavior Rating Scale by Burdock et al. (1960), revised and retitled Ward Behavior Inventory (WBI; Burdock \& Hardesty, 1968b); the Hamilton Psychiatric Rating Scale for Depression (1960); the Katz Adjustment Scales (1963); the Inpatient Multidimensional Psychiatric Scale (IMPS; Lorr, Klett, \& McNair, 1963; Lorr, McNair, Klett \& Lasky, 1966); a package of psychiatric evaluation forms developed by Spitzer and Endicott (1971); and the Structured Clinical Interview (SCI; Burdock \& Hardesty, 1962, 1968a, 1968b) 
developed out of an earlier interview Behavior Rating Scale (1960).

This report compares observations of the behavior of a sample of acutely ill schizophrenic patients by a team of psychiatrists with concomitant observations by a team of psychologists. The psychiatrists were engaged in carrying out observations as part of a controlled double-blind study of the efficacy of different phenothiazines for treatment of acute schizophrenia. The findings with respect to drug efficacy have been reported elsewhere (Goldberg et al., 1972). The data presented here illustrate the complementariness between the psychodiagnostician and the therapist in the evaluation of psychopathology. The therapist's judgments are focused on a treatment plan for the patient, while the psychodiagnostician (like the laboratory scientist) is ideally concerned only with a systematic evaluation of the patient's psychopathological behavior. Moreover, the psychodiagnostician's contribution to the understanding of the patient's psychopathology is likely to be most helpful when it is carried out without being influenced by the therapist's conclusions (Payne, 1957; Shapiro, 1951). If allowance is made for the necessary element of independence in the two sets of judgments, the results of such a comparison can be interpreted as evidence for the congruent validity of the SCI on which the psychologists recorded their findings. The criterion was psychiatric judgments on the IMPS.

\section{Method}

\section{Instruments}

Evaluations by the psychiatrists were made on a special variant of the first edition of the IMPS which had been prepared by the Psychopharmacology Research Branch of the NIMH. This special edition contained 80 items instead of the 75 items of the original edition, the extra items having been contributed by the NIMH staff. The psychologists used the SCI.

The IMPS. The items of the IMPS describe behavior observed or reported by the patient during a free clinical interview; a few of the items refer to the previous week. Most of the items are rated on a 9-point scale, some are on a 5-point scale, and others are dichotomous. The IMPS is designed to be used with hospitalized mental patients capable of being interviewed (Lorr et al., 1963). A number of studies attest to the reliability and validity of the IMPS (Lorr, 1953; Lorr et al., 1963; Lorr et al., 1966). The IMPS yields scores on 10 syndromes: excitement, hostile belligerence, paranoid projection, grandiose expansiveness, perceptual distortion, anxious intropunitiveness, retardation and apathy, disorientation, motor disturbance, and conceptual disorganization. The syndromes of the IMPS have been constructed by means of a factor analysis (Lorr et al., 1963) in which an oblique reference system was chosen (allowing for intercorrelations among the syndromes). Thus, standard scores on the syndromes show the extent to which a patient deviates from the norm group of hospitalized psychotics.

The SCI. The SCI, in contrast, is intended for evaluation of maladaptive behaviors both in screening in the community and in measurement of change in office, clinic, or hospital. The SCI has a completely structured input which the clinician must learn to administer in an unstilted conversational tone; the input is openended, non-directive, and aimed at achieving comprehensiveness without affront to a person's privacy or desire to be reticent. The interviewer makes dichotomous judgments of maladaptive behavior on an inventory of 179 behavioral items in the course of the interview. The procedure takes about 15 to 20 minutes. The controlled input allows the interviewer to devote much more attention to the nuances of the subject's behavior, verbalizations, and appearance than is usually possible in an unstructured interview, because the interviewer is not required to make decisions about how to respond to the subject.

The $\mathrm{SCI}$ is scored on the following 10 subtests: anger-hostility, conceptual dysfunction, fear-worry, incongruous behavior, incongruous ideation, lethargy-dejection, perceptual dysfunc- 
tion, physical complaints, self depreciation, and sexual problems. An eleventh score, level, is the mean standard score of the other 10 . The subtests were constructed by sorting items into the 10 clusters on rational grounds, checking the allocation of each item by correlating the item with the rest of the subtest and with each of the other subtests, reassigning items where necessary, and verifying the final assignments by correlation on independent samples.

Unlike the IMPS, whose norms are based on psychotic inpatients, the SCI was standardized on normal persons in the community (Burdock \& Hardesty, 1968a, 1969b). Standard scores on the subtests of the SCI, therefore, show the amount of deviation from normals. The reliability of the SCI has been reported in a number of studies (Burdock \& Hardesty, 1966, 1968a, $1969 \mathrm{~b}$ ), as have validity in distinguishing various degrees of pathology and in measuring change (Burdock \& Hardesty, 1969b), and applications to evaluation of treatment (Burdock \& Hardesty, 1969a) and to psychopharmacological research (Hardesty \& Burdock, 1972). The SCI has proven particularly useful as a technique for assessment of patients by an external evaluator because it is objective, ahistorical, and can be repeated to determine changes.

\section{Procedure}

The IMPS is usually filled out after a free clinical interview with the patient. In this instance, however, the psychiatrists sat in with the psychologists, while the latter conducted the Structured Clinical Interview. By this means, the timing, the specific questions, and the general circumstances under which the evaluations were carried out were made similar for the psychiatrists and the psychologists without impairment of the design of the drug study.

The 72 patients in the sample were evaluated in joint sessions by the psychologists and psychiatrists at baseline, prior to administration of treatment. A second evaluation was carried out at termination of treatment approximately four weeks later, under the same arrangements as the first, on 58 of the original patients. (Fourteen patients had to be evaluated separately by the psychologists and the psychiatrists because of scheduling problems.) The psychiatrists rated the patients on the IMPS, basing their judgments on the verbal material and behavior produced by the patients during the SCI interview conducted by the psychologist. The psychologists recorded their judgments on the items of the SCI.

The patient was brought in for the baseline evaluation after a washout period of two to four days to eliminate residual effects of previously ingested drugs. The interview was conducted by one or the other of two psychologists, both of whom independently filled in the inventory part of the SCI. Two senior psychiatrists sat in at the psychological interview and rated the patient's behavior on the IMPS. In this study the psychologists had no other information, except for the knowledge that all patients in the study were schizophrenic, and no further interaction with the patients. After the patients had been under treatment for four weeks, 58 of them were reevaluated under the same conditions as in the first interview.

\section{Results}

\section{Reliability}

Inter-observer agreement was calculated by two-way intraclass correlation on subsamples of the patients for a pair of psychologists on the SCI and for two pairs of psychiatrists on the IMPS. Table 1 shows the correlations between the psychologists on the 10 subtests and level score of the SCI and also between each pair of psychiatrists on the 10 syndromes of the IMPS. The correlations are based on the largest number of paired ratings available for the psychologists and on two separate sets of paired ratings for the psychiatrists. Because of scheduling conflicts, the psychiatric raters alternated more frequently than the psychologists, so that no more than 10 sets of ratings could be assembled on 


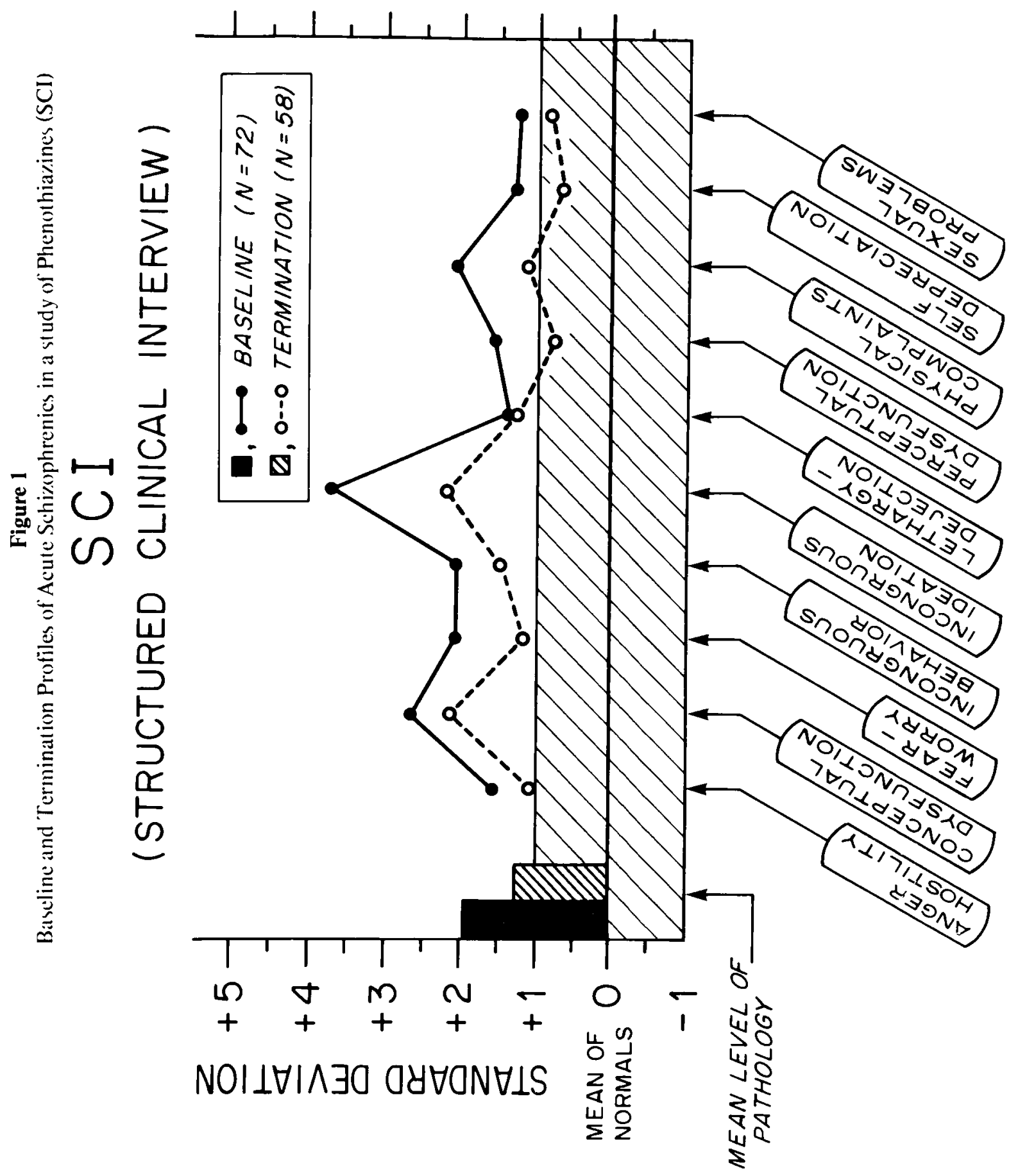

Downloaded from the Digital Conservancy at the University of Minnesota, http://purl.umn.edu/93227. 
Table 1

Intraclass Correlations Between Two Raters

\begin{tabular}{|c|c|c|c|c|}
\hline \multicolumn{2}{|c|}{ Structured Clinical Interview SCI } & \multicolumn{3}{|c|}{ Inpatient Multidimensional Psychiatric Scale IMPS } \\
\hline Subtest & $\begin{array}{c}\mathrm{R} \\
(\mathrm{N}=38) \\
\end{array}$ & Syndrome & $\begin{array}{c}\mathrm{R} \\
(\mathrm{N}=10)\end{array}$ & $\begin{array}{c}\mathrm{R} \\
(\mathrm{N}=10)\end{array}$ \\
\hline 1. Anger-Hostility & .83 & 1. Eisitement & .88 & .94 \\
\hline 2. Conceptual Dysfunction & .75 & 2. Hostile Belligerence & .96 & .85 \\
\hline 3. Fear-Worry & .69 & 3. Paranoid Projection & .22 & .96 \\
\hline 4. Incongruous Behavior & .71 & 4. Grandiose Expansiveness & .97 & --- \\
\hline 5. Incongruous Ideation & .71 & 5. Perceptual Distortion & .80 & --- \\
\hline 6. Lethargy-Dejection & .78 & 6. Anxious Intropunitiveness & .62 & .63 \\
\hline 7. Perceptual Dysfunction & .75 & 7. Retardation and Apathy & .40 & .73 \\
\hline 8. Physical Complaints & .64 & 8. Disorientation & --- & --- \\
\hline 9. Self Depreciation & .67 & 9. Motor Disturbance & -- & .63 \\
\hline $\begin{array}{l}\text { 10. Sexual Problems } \\
\text { Leve1 }\end{array}$ & $\begin{array}{l}.63 \\
.96\end{array}$ & 10. Conceptual Disorganization & .77 & .77 \\
\hline
\end{tabular}

any pair of psychiatrists. Because of the occurrence of zero scores, no correlations could be calculated for two subtests in one set of paired psychiatric ratings or for three subtests in the other.

\section{Score Profiles}

$S C I$. Figure 1 presents the baseline and termination mean clinical profiles of the patients on the 10 subtests of the $\mathrm{SCI}$ as recorded by the psychologists. The subtests are scaled in standard scores units, with the zero points determined by the mean standard scores (after a curvefitting transformation) of a reference group of normal community subjects. Since about $80 \%$ of normals score below 1 standard deviation, scores above one standard deviation are to be regarded as significant evidence of maladaptive behavior on that variable. The relatively high mean scores on the profile presented in Figure 1 tend to be quite representative of schizophrenics selected for drug studies: the patients are affectively charged and show florid symptomatology, thought disorder, and delusions.

In an analysis of a pooled group of 74 schizophrenics who were members of chlorpromazine control groups in five different drug studies, Hardesty and Burdock (1972) identified an SCI profile typical of acute schizophrenia: incongruous ideation (delusions and affective dis- sonance), conceptual dysfunction, and incongruous behavior, in that order. Perceptual dysfunction (hallucinations) is often elevated above onc standard deviation, as in this instance: but only about one-third of acute schizophrenics admitted to Bellevue Psychiatric seem to show active hallucinations at admission interview. Termination profiles in previous studies with phenothiazines have generally reflected an across-the-board downward drift in all areas of pathology, with the same subtests dominating the shape of the profile. Since the group shown in Figure 1 includes some placebo patients, the improvement at termination is not as marked as in other studies.

IMPS. Figure 2 gives the baseline and termination profiles of the patients on the 10 syndromes of the IMPS as recorded by the psychiatrists who sat in at the SCI interviews. The IMPS profile is characteristic of schizophrenic patients, with highest evaluations in paranoid projection, perceptual distortion, and conceptual disorganization. The IMPS $T$-scores appear less elevated at baseline than the SCI standard scores in Figure 1, because they are based on a norm group of mental hospital inpatients instead of non-patients. At termination, all the scores had declined below the mean of the norm group. Both the IMPS and the SCI protiles are typical of schizophrenic profiles seen in previous empirical studies and would be interpreted as 


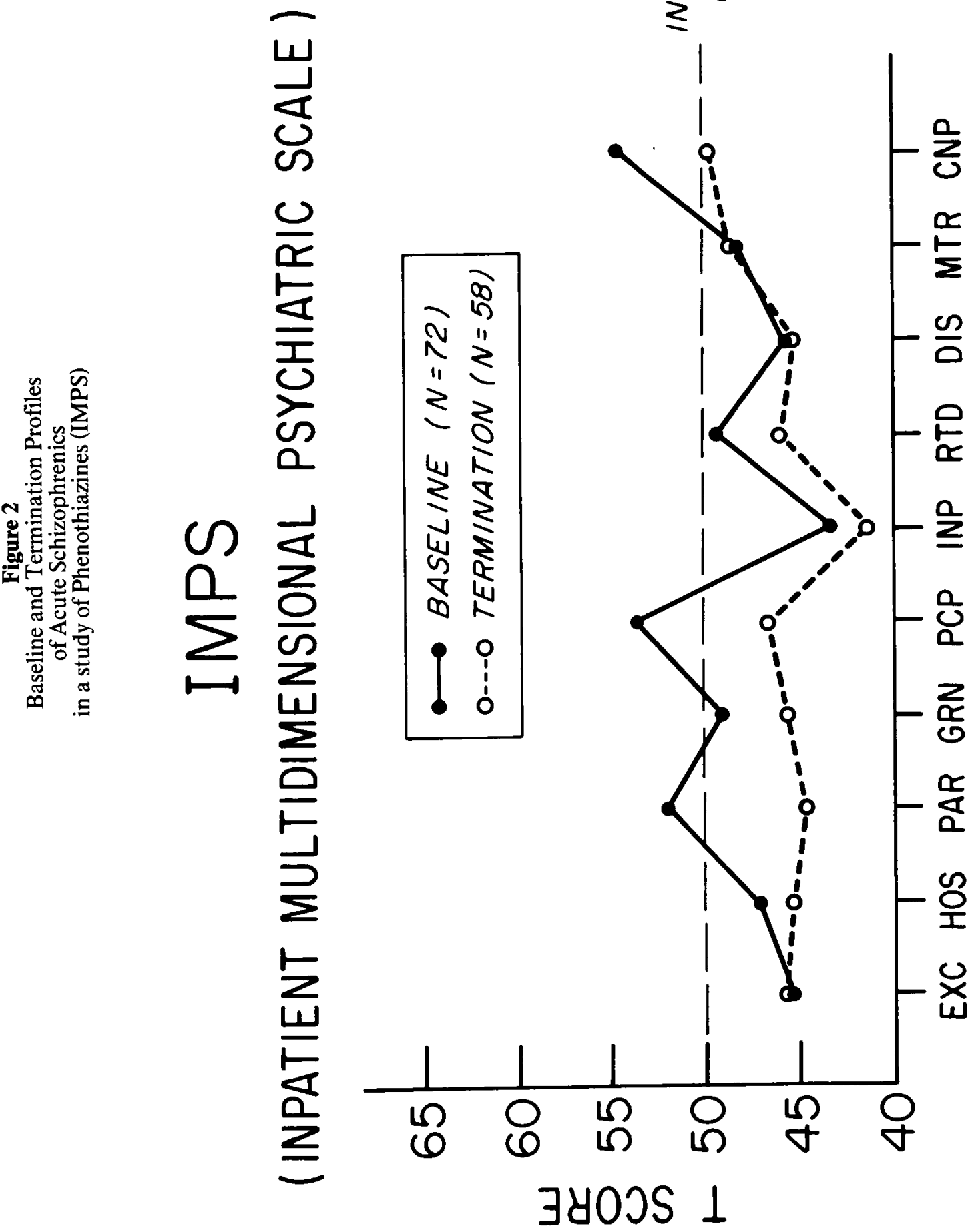

Downloaded from the Digital Conservancy at the University of Minnesota, http://purl.umn.edu/93227. 
Table 2

Means and Standard Deviations of Variables

\begin{tabular}{lrrrr}
\hline & \multicolumn{2}{l}{ Baseline $(\mathrm{N}=72)$} & \multicolumn{2}{c}{ Termination $(\mathrm{N}=58)$} \\
\cline { 2 - 3 } Variable & Mean & S.D. & & \multicolumn{1}{c}{ Mean } \\
IMPS & & & & \\
EXC & 45.39 & 6.76 & 45.57 & 8.82 \\
HOS & 47.26 & 7.90 & 45.50 & 10.29 \\
PAR & 52.08 & 9.21 & 44.72 & 9.54 \\
GRN & 49.03 & 9.29 & 45.97 & 4.39 \\
PCP & 53.99 & 13.36 & 46.53 & 8.59 \\
INP & 43.46 & 6.92 & 41.48 & 5.36 \\
RTD & 49.89 & 8.79 & 46.12 & 7.23 \\
DIS & 45.56 & 1.44 & 45.53 & 1.30 \\
MTR & 48.19 & 8.96 & 48.53 & 11.11 \\
CNP & 54.79 & 12.34 & 49.86 & 12.44 \\
SCI & & & & \\
A-H & 1.57 & 1.21 & 1.09 & 1.48 \\
CD & 2.67 & 1.14 & 2.16 & 1.43 \\
F-W & 2.06 & 1.17 & 1.12 & 1.44 \\
IB & 2.03 & 1.55 & 1.45 & 1.77 \\
II & 3.77 & 1.40 & 2.21 & 2.01 \\
L-D & 1.35 & .82 & 1.24 & .99 \\
PD & 1.55 & 1.63 & .75 & 1.42 \\
PC & 2.11 & 1.68 & 1.18 & 1.78 \\
SD & 1.30 & .86 & .65 & 1.01 \\
SP & 1.22 & 1.42 & .85 & 1.41 \\
\hline
\end{tabular}

clinically similar. Table 2 lists the means and standard deviations of both sets of variables at baseline and at termination. Comparison of baseline with termination standard deviations disclosed no overall diminution in variability for either instrument.

Baseline and termination correlations. Table 3 shows the bivariate intercorrelations between the syndromes of the IMPS and the subtests of the SCI at baseline and at termination. Correlations not reaching the $5 \%$ level of significance have been omitted from Table 3. Comparison of the upper and lower parts of Table 3 reveals an increased number of significant bivariate correlations among the two in- struments from 19 at baseline to 35 at termination. Moreover, most of the correlations at termination were larger than the corresponding correlations at baseline. Furthermore, the two negative correlations that appeared at baseline were not significant at termination.

The evidence of Figures 1 and 2, together with that of Tables 2 and 3 , suggests that psychiatrists and psychologists made somewhat more similar judgments on the termination ratings than on the baseline ratings. The IMPS syndromes and the SCI subtests maintained approximately the same relative positions at termination as at baseline, but the SCI profiles showed a more noticeable parallelism. 
Table 3

Intercorrelations of Variables

\begin{tabular}{|c|c|c|c|c|c|c|c|c|c|c|}
\hline \multirow{2}{*}{ IMPS } & \multicolumn{10}{|c|}{ SCI } \\
\hline & $\overline{\mathrm{A}-\mathrm{H}}$ & $\mathrm{CD}$ & $\mathrm{F}-\mathrm{W}$ & IB & II & $\mathrm{L}-\mathrm{D}$ & PD & $\mathrm{PC}$ & $\mathrm{SD}$ & SP \\
\hline \multicolumn{11}{|c|}{ BASELINE $(\mathrm{N}=72)$} \\
\hline EXC & $.40 * *$ & .27 & - & - & $.27 *$ & - & - & $.33 * *$ & - & - \\
\hline HOS & $.29 *$ & - & - & $-.26 *$ & - & - & - & - & - & - \\
\hline PAR & - & - & - & - & - & - & - & - & - & - \\
\hline GRN & - & - & - & - & $.28 *$ & - & - & - & - & - \\
\hline PCP & - & - & - & - & - & - & $.47 * *$ & - & - & - \\
\hline INP & - & $-.36 * *$ & $.36 * *$ & - & - & - & - & - & $.43 * *$ & - \\
\hline RTD & - & $.29 *$ & - & - & - & $.46 * *$ & - & - & - & - \\
\hline DIS & - & - & - & - & - & - & - & - & - & - \\
\hline MTR & - & - & - & $.37 * \star$ & - & - & - & - & - & - \\
\hline $\mathrm{CNP}$ & $.23 *$ & $.50 * *$ & - & - & $.32 * *$ & - & $.35 * *$ & - & - & $.23 *$ \\
\hline \multicolumn{11}{|c|}{ TERMINATION $(\mathrm{N}=58)$} \\
\hline EXC & $.38 * \star$ & $.49 * *$ & $.32 *$ & $.42 * *$ & - & - & $.26 *$ & - & - & $.38 * *$ \\
\hline HOS & $.51 * *$ & $.36 * *$ & - & - & $.45 * \star$ & - & $.54 * *$ & - & - & - \\
\hline PAR & $.37 \star \star$ & $.40 * \star$ & - & - & $.53 * *$ & - & $.56 * *$ & - & - & - \\
\hline GRN & $.40 * *$ & $.36 * *$ & - & - & $.45 * *$ & - & - & - & - & - \\
\hline PCP & $.39 * *$ & - & $.36 * *$ & $.31 *$ & $.26 *$ & - & $.64 * *$ & - & $.26 *$ & - \\
\hline INP & - & - & $.38 * *$ & - & - & - & - & - & $.27 *$ & - \\
\hline RTD & - & - & - & - & - & $.58 * *$ & $.32 *$ & - & - & - \\
\hline DIS & - & - & - & - & - & - & - & - & - & - \\
\hline MTR & - & - & - & $.47 * *$ & - & - & - & - & - & - \\
\hline CNP & $.43 * *$ & $.59 * *$ & $.27 *$ & $.48 * *$ & $.38 * *$ & - & - & - & $.30 *$ & $.33 *$ \\
\hline
\end{tabular}

Note. Indicates $r<.26 ; p>.05$.

$\star p<.05$

$\star * p<.01$

\section{Canonical Correlation Analysis}

The relation between the psychological and psychiatric assessments, i.e., between the two sets of 10 subtests each, was investigated by means of canonical correlation (Cooley \& Lohnes, 1971, pp. 168-200). Table 4 reports the results of the canonical analyses both for baseline and for termination scores. The first roots yielded a canonical correlation of $.84(p<.001)$ for baseline measures and a canonical correlation of .86 $(p<.001)$ for scores at termination. The fact that the correlation obtained at baseline was replicated at termination is evidence for the reliability of the obtained relation. Table 4 also lists two additional roots at baseline and three more at termination which were significant. The second roots at baseline and termination yielded canonical correlations of .78 and .76 , respectively; the third roots gave correlations of .68 and .69; the last significant root, the fourth at termination, produced a canonical correlation of .64 . Since each successive root, with its corresponding canonical correlation, is independent of those previously extracted, a substantial amount of agreement between the psychiatric and the psychological assessments was revealed.

Table 5 lists the first canonical correlations at baseline and termination respectively, together 
with the weights and the correlations for each subtest and syndrome. The weights are the proportions of each IMPS syndrome or SCI subtest entered into the canonical correlation. The correlations alongside the weights show the amount of agreement that each IMPS syndrome or SCI subtest has with its own side.

The interpretation of a canonical correlation depends on the largest weights that entered into it. On the IMPS (psychiatric) side the canonical variate was bipolar and composed principally of anxious-intropunitiveness in the negative direction and of retardation-apathy and conceptual disorganization in the positive direction, i.e., the patients were identified by the presence of retardation-apathy and conceptual disorganization and by the absence of anxious intropunitiveness.
The psychological canonical variate derived from the SCI was composed essentially of four weights and was also bipolar. The SCI subtests for self depreciation and fear-worry on the negative side, taken together, correspond to the IMPS syndrome for anxious-intropunitiveness; however, on the positive side, in addition to conceptual dysfunction and lethargy-dejection (corresponding to retardation-apathy on the IMPS), there was also perceptual dysfunction. At the outset of the interviewing, the psychiatric judges were dissatisfied because of the absence of specific stimuli in the protocol for eliciring evidence of hallucinations. Accordingly, it was arranged that they would ask additional questions about hallucinatory experiences (after the standard interview, so the comparison of the two tech-

Table 4

Canonical Correlations between IMPS and SCI

\begin{tabular}{|c|c|c|c|c|}
\hline $\begin{array}{l}\text { Number of Roots } \\
\text { Removed }\end{array}$ & $\begin{array}{l}\text { Corresponding } \\
\text { Canonical } \mathrm{R} \\
\end{array}$ & $x^{2}$ & df & p \\
\hline \multicolumn{5}{|l|}{ BASELINE $(\mathrm{N}=72)$} \\
\hline 0 & .84 & 75.94 & 19 & $<.001$ \\
\hline 1 & .78 & 58.43 & 17 & $<.001$ \\
\hline 2 & .68 & 37.94 & 15 & $<.01$ \\
\hline 3 & .52 & 19.44 & 13 & .11 \\
\hline 4 & .49 & 16.65 & 11 & .12 \\
\hline 5 & .41 & 11.07 & 9 & .27 \\
\hline 6 & .32 & 6.59 & 7 & .53 \\
\hline 7 & .15 & 1.40 & 5 & .92 \\
\hline 8 & .10 & 0.61 & 3 & .89 \\
\hline 9 & .04 & 0.11 & 1 & .73 \\
\hline \multicolumn{5}{|c|}{ TERMINATION $(\mathrm{N}=58)$} \\
\hline 0 & .86 & 65.43 & 19 & $<.001$ \\
\hline 1 & .76 & 40.36 & 17 & $<.01$ \\
\hline 2 & .69 & 30.94 & 15 & $<.01$ \\
\hline 3 & .64 & 25.02 & 13 & $<.05$ \\
\hline 4 & .50 & 13.46 & 11 & .27 \\
\hline 5 & .46 & 11.44 & 9 & .25 \\
\hline 6 & .37 & 7.15 & 7 & .41 \\
\hline 7 & .27 & 3.70 & 5 & .60 \\
\hline 8 & .16 & 1.31 & 3 & .73 \\
\hline 9 & .08 & .34 & 1 & .57 \\
\hline
\end{tabular}




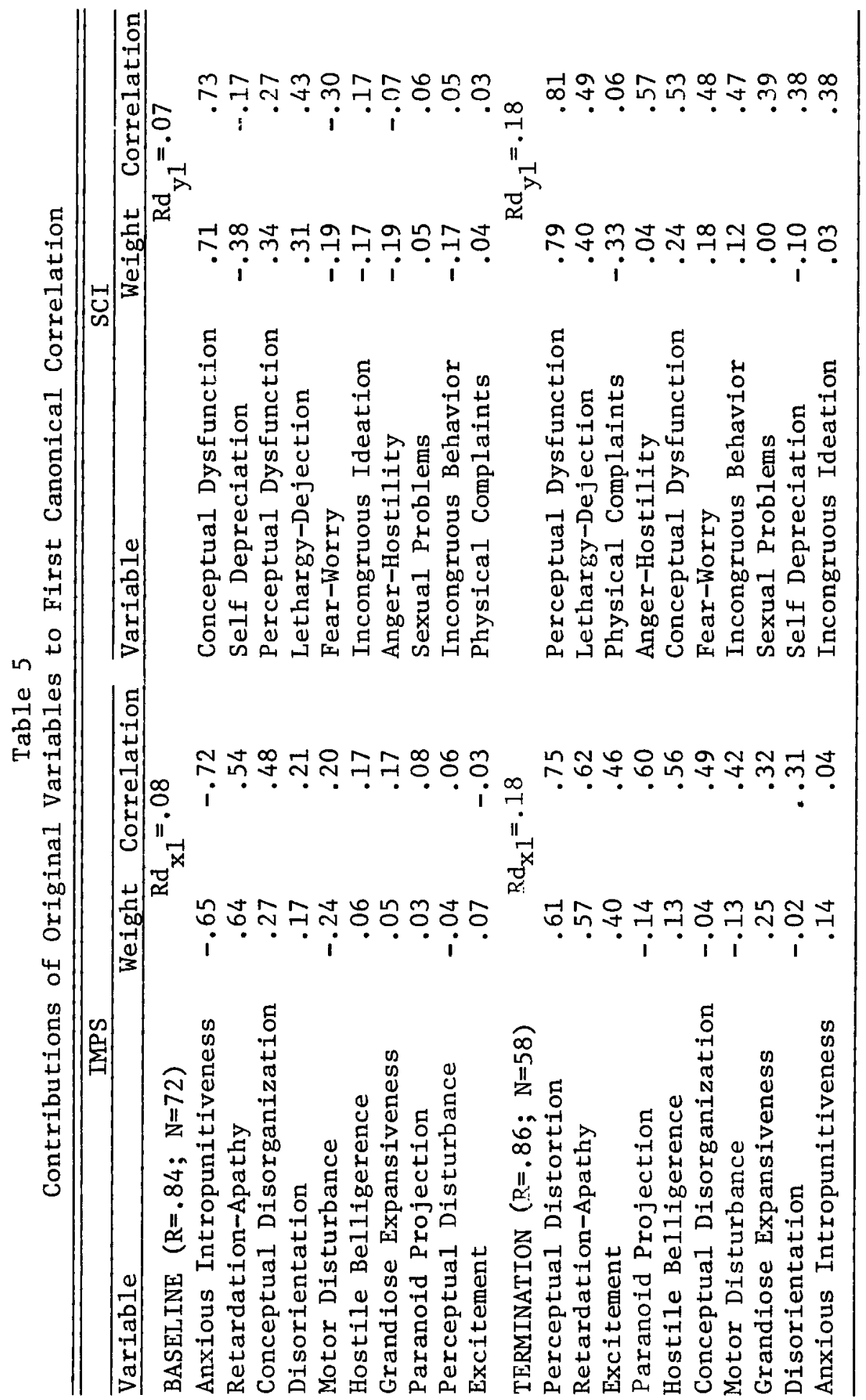

Downloaded from the Digital Conservancy at the University of Minnesota, http://purl.umn.edu/93227. 
niques would not be biased). By the time of the termination interview, the psychiatrists made less use of the opportunity for supplementary questions about hallucinations. For the termination ratings the two sets of weights (IMPS and $\mathrm{SCl}$ ) both showed strong components for hallucinations (perceptual distortion vis-à-vis perceptual dysfunction), as well as for retardationapathy (lethargy-dejection on the SCI).

Table 5 also shows the redundancy coefficients, $R d$, for each side (Stewart \& Love, 1968). The subscripts, $x$ and $y$, refer to the IMPS and SCI, respectively; the subscript number, 1, signifies that these redundancy coefficients correspond to the first canonical correlation. The redundancy coefficient measures the proportion of the variance accounted for by the other set of variables. Although in general the redundancy coefficients of each set of variables were not equal, in this instance they were approximately the same, both at baseline (.08 for the IMPS vs. .07 for the $\mathrm{SCl}$ ) and at termination (.18 for both techniques).

Table 6 lists the complete set of redundancy coefficients. There is one for each technique for each of the ten roots extracted at baseline and at termination. The sum of the ten redundancy co- efficients for each set of variables is a measure of the total proportion of variance accounted for by the other set when all ten possible latent roots have been extracted. The totals in Table 6 reveal that for the baseline ratings, approximately $30 \%$ of the variance of each set of variables was accounted for by the other set; for the ratings at termination the proportion of variance accounted for by each set increased to about $40 \%$. Moreover, the approximate equality of the two totals both at baseline and at termination indicated that the contributions of the two techniques were symmetrical.

\section{Summary and Conclusions}

The ratings by a team of psychologists on the SCI and by a team of psychiatrists on the IMPS were made simultaneously while one of the psychologists conducted the structured interview of the SCI. In this way 72 acute schizophrenics were rated shortly after admission to a psychiatric hospital; 58 of them were re-rated approximately one month later in a replication of the original procedure. The SCI profile at termination showed that the patients were still significantly outside community norms in level of psy-

Table 6

Redundancy Values at Baseline and Termination

\begin{tabular}{|c|c|c|}
\hline & \multicolumn{2}{|c|}{ Termination } \\
\hline & $\mathrm{APS}-\mathrm{Rd}$ & $\mathrm{SCI}^{-\mathrm{Rd}} \mathrm{y}_{\mathrm{y}}$ \\
\hline & .1816 & .1798 \\
\hline & .0646 & .0544 \\
\hline & .0625 & .0757 \\
\hline & .0249 & .0313 \\
\hline & .0249 & .0197 \\
\hline & .0164 & .0209 \\
\hline & .0109 & .0136 \\
\hline & .0047 & .0040 \\
\hline & .0020 & .0011 \\
\hline & .0005 & .0006 \\
\hline 1 & .3930 & .4011 \\
\hline
\end{tabular}


chopathology and that they retained the typical schizophrenic peaks in incongruous ideation and conceptual dysfunction; the IMPS profile showed that the patients had dropped below the mean of that norm group of hospitalized mental patients and that the highest scores were conceptual disorganization and motor retardation. Both instruments agreed with the conclusion that after treatment with phenothiazines, the patients, on the average, showed less severe symptoms but were still observably ill and in need of further care.

Two canonical analyses were carried out, one on the initial ratings, the second on the replication. Canonical correlations of .84 and .86 were obtained, respectively, for the first latent roots at each occasion. Successive significant roots yielded correlations of .78 and .68 on the initial ratings and $.76, .69$, and .64 on the follow-up ratings. After all 10 latent roots had been extracted for each occasion of rating, redundancy coefficients were calculated for each instrument. The results showed that for the initial ratings, $30 \%$ of each instrument's variance could be explained by the other instrument; at the followup ratings the redundancies had increased to $40 \%$ on each side. The contributions of the two techniques to the canonical correlation were approximately equal, as indicated by the symmetry in the respective redundancy coefficients. These results indicate a substantial amount of agreement between the two sets of judgments.

Because of differences in training, professional attitude, and responsibilities, assessments of psychopathology by psychiatrists and psychologists may be expected to show differences, even when judgments are made simultaneously from a structured interview. Another reason for differences between the IMPS and the SCI lies in the design of the two instruments. This version of the IMPS consisted of 84 items-some molar, some molecular-whereas all 179 items of the SCI are molecular. Some items of the IMPS refer to the observation period, others refer to the past week; but all items of the SCI refer to the observation period. Items of the
IMPS are graded variously on 9-point, 5-point, or 2-point scales, but all items of the SCI are dichotomous. A third factor tending to reduce the correlation between the two techniques is the different reference populations: the IMPS is normed on a reference population of hospitalized mental patients, mostly schizophrenics, while the SCI is standardized on normal persons in the community. The results are offered as evidence for the congruent validity of the SCI.

\section{References}

Burdock, E. I., Hakerem, G., Hardesty, A. S., \& Zubin, J. A Ward Behavior Rating Scale for mental hospital patients. Journal of Clinical Psychology, 1960, 16, 246-247.

Burdock, E. I., \& Hardesty, A. S. Interview Behavior Rating Scale. NY: New York State Psychiatric Institute, 1960.

Burdock, E. I., \& Hardesty, A. S. Structured clinical interview and inventory. Paper presented at the meeting of the Eastern Psychological Association, Atlantic City, May, 1962.

Burdock, E. I., \& Hardesty, A. S. Behavior patterns of chronic schizophrenics. In P. H. Hoch and J. Zubin (Eds.), Psychopathology of schizophrenia. NY: Grune and Stratton, 1966.

Burdock, E. I., \& Hardesty, A. S. A psychological test for psychopathology. Journal of Abnormal Psychology, 1968, 73, 62-69. (a)

Burdock, E. I., \& Hardesty, A. S. Ward Behavior Inventory Manual. NY: Springer, 1968. (b)

Burdock, E. I., \& Hardesty, A. S. A research tactic for evaluation of drug specificity in schizophrenia. In D. V. Siva Sankar (Ed.), Schizophrenia: Current concepts and research. Hicksville, NY: P. J. D. Publications, 1969. (a)

Burdock, E. I., \& Hardesty, A. S. Structured Clinical Interview Manual. NY: Springer, 1969. (b)

Cooley, W. W., \& Lohnes, P. R. Multivariate data analysis. NY: Wiley, 1971.

Goldberg, S. C., Frosch, W. A., Drossman, A. K., Schooler, N. R., \& Johnson, G. F. S. Prediction of response to phenothiazines in schizophrenia-a cross validation study. Archives of General Psychiatry. 1972, 26. 367-373.

Hamilton, M. A rating scale for depression. Journal of Neurology. Neurosurgery, and Psychiatry. $1960,23,56-62$.

Hardesty, A. S., \& Burdock, E. I. Application of a pooled standard treatment group to evaluation of 
drug trials. Psychopharmacology Bulletin, 1972, 8. 23.

Katz, M. M., \& Lyerly, S. B. Methods for measuring adjustment and social behavior in the community. Psychological Reports, 1963, 13, 503-535.

Klett, C. J. Assessing change in hospitalized psychiatric patients. In P. McReynolds (Ed.), Advances in psychological assessment (Vol. 1). Palo Alto, CA: Science and Behavior Books, 1968.

Lorr, M. Multidimensional scale for rating psychiatric patients. Hospital Form. Veterans Administration Technical Bulletin, 1953, 43, 10-507.

Lorr, M. Rating scales and check lists for the evaluation of psychopathology. Psychological Bulletin. $1954,51,119-127$.

Lorr, M., Klett, C. J., \& McNair, D. M. Syndromes of psychosis. NY: Macmillan, 1963.

Lorr, M., McNair, D. M., Klett, C. J., \& Lasky, J. J. Inpatient Multidimensional Psychiatric Scale (Rev.). Palo Alto, CA: Consulting Psychologists Press, 1966.

Lyerly, S. B. Handbook of psychiatric rating scales (2nd ed.). Rockville, MD: NIMH, 1973.

McReynolds, P., \& Ferguson, J. T. Clinical manual for the Hospital Adjustment Scale. Palo Alto, CA: Consulting Psychologists Press, Inc., 1953.

Overall, J. E., \& Gorham, D. R. The brief psychiatric rating scale. Psychological Reports, 1962, 10. 799-812.

Payne, R. W. Experimental method in clinical psychological practice. Journal of Mental Science. 1957, 103, 189-196.
Shapiro, M. B. An experimental approach to diagnostic psychological testing. Journal of Mental Science, 1951, 97, 748-764.

Spitzer, R., \& Endicott, J. An integrated group of forms for automated psychiatric case records. $A r$ chives of General Psychiatry, 1971, 24, 540-547.

Stewart, D. K., \& Love, W. A. A general canonical correlation index. Psychological Bulletin, 1968, $70,160-163$.

Wittenborn, J. R. Manual: Wittenborn Psychiatric Rating Scales. NY: The Psychological Corporation, 1955.

\section{Acknowledgements}

This study was supported in part by NIMH grant MH 14113. The authors wish to express their appreciation to Dr. Gordon Johnson, Mrs. Judy Calhoun, and Dr. William Davis for their participation in the conduct of the interviews; to Mrs. Ann Drossman for her assistance with the logistics of the study; and to Dr. Solomon C. Goldberg. Assistant Chief, Psychopharmacology Research Branch, for facilitating incorporation of this study in his study, Prediction of Response to Phenothiazines in Schizophrenia.

\section{Author's Address}

Eugene I. Burdock, Department of Psychiatry, New York University Medical Center, 550 First Avenue, New York, NY 10016. 